\title{
Dementia presenting with aphasia: clinical characteristics
}

\author{
Mario F Mendez, Beth A Zander
}

\begin{abstract}
Dementia, a disorder of multiple cognitive functions, may atypically present as an aphasia. The clinical characteristics are reported of 13 patients with up to 14 years of progressive language impairment before developing dementia. In reviewing the literature, it was found that these patients were similar to those reported with progressive aphasia. It is concluded that dementia may present with an anomic, dysfluent language disorder due to the focal left sylvian onset of several dementing illnesses.
\end{abstract}

Recent reports indicate that dementia may begin with an isolated language disorder before progressing to involve other cognitive deficits. ${ }^{12}$ Case reports of an isolated language disturbance have appeared in the recent literature as "Slowly Progressive Aphasia" (SPA); and some of these patients have become demented. ${ }^{3-6}$ These reports raise many questions about the clinical characteristics of these patients. It is unclear whether this is a single language disorder or whether this is a heterogeneous group of patients with different clinical subtypes. It is also unclear how often a progressive aphasia usually heralds the onset of dementia. Further clinical characterisation of patients with dementia presenting with aphasia may also help clarify the nature of SPA, the focus of pathology, and the potential causes of this disorder.

We studied the clinical features of 13 patients with a language disorder of up to 14 years duration, who subsequently developed dementia. These patients were evaluated with neurological, neuropsychological, and neuroimaging techniques and long-term follow up. We report the results, compare them with the reported cases of SPA, and suggest that these patients develop an anomic, dysfluent aphasia due to the focal left sylvian onset of several possible conditions causing dementias.

Neurology, St Pau

Ramsey Medical

Center and The

University of

Minnesota, St Paul, Minnesota, USA

M F Mendez

B A Zander

Correspondence to: Dr Mendez,

Department of Neurology, St Paul-Ramsey Medical Center, 640 Jackson Street, St Paul, MN 55101, USA.

Received 13 June 1990 and in revised form 15 October 1990.

Accepted 15 November 1990

\section{Methods}

We evaluated 13 patients who presented with a relatively isolated and progressive language disturbance. Neurological examination, laboratory studies, and CT or MR head scans were performed, and specific focal lesions such as stroke or tumour were excluded. The patients also had neuropsychological testing including a language evaluation to characterise their deficits. We defined anomia as word-finding pauses in conversational speech and decreased confrontational naming. We defined dysfluency as an overall decrease in word production without effective substitutions or circumlocutions, effort or struggle, agrammatism, dysprosody, and/or dysarthria. Finally, we summarised the findings in 56 cases of SPA found in the literature and compared them with our patients.

\section{Results}

The 13 right handed patients (eight women, five men) had a median age of 64 at onset of their language disturbance (see table 1). They presented with anomia (9), dysfluency (3), and agraphia (2) for one to 14 years (median of two years) before evidence of other cognitive disturbances sufficient to constitute dementia. In addition to anomia and/or dysfluency, all thirteen patients had relatively preserved auditory comprehension, paraphasias with phonemic substitutions, and preserved insight into their language disorder. Other associated characteristics are summarised in table 1 . The findings were similar to the cases of SPA found in the literature (see table 2). Four illustrative case reports follow.

\section{Patient 1}

The patient was a 68 year old female physician, with a year of progressive word-finding difficulties. She also complained of problems with writing and with calculations. Although she could form long grammatically correct sentences, she omitted key words from her conversation. When describing her activities, she said: "I was an impaired physician so I thought I better ... I do keep ... I'm going with . . . I wouldn't want the kids because they ... they want to ..." Word-finding on confrontational naming was also impaired. Repetition was severely affected, but she could comprehend four-step commands and complex material. Writing was severely impaired, and reading was slow and laboured. She had normal attention, orientation, constructions, praxis, right-left discrimination, fund of knowledge, and insight into her deficits. She could not, 
Table 1 Clinical characteristics of 13 patients

\begin{tabular}{|c|c|c|c|c|c|c|}
\hline \multicolumn{2}{|l|}{ Patient } & \multirow[b]{2}{*}{$\begin{array}{l}\text { Age-onset } \\
\text { /dementia }\end{array}$} & \multirow{2}{*}{$\begin{array}{l}\text { Initial } \\
\text { symptom }\end{array}$} & \multirow{2}{*}{$\begin{array}{l}\text { Other features: } \\
C A L, W R T, R E P, O B A^{\star}\end{array}$} & \multirow[b]{2}{*}{$\begin{array}{l}R \text { Motor } \\
\text { and reflex }\end{array}$} & \multirow[b]{2}{*}{$\begin{array}{l}\text { L Sylvian } \\
\text { atrophy }\end{array}$} \\
\hline Number & Sex & & & & & \\
\hline $\begin{array}{r}1 \\
2 \\
3 \\
4 \\
5 \\
6 \\
7 \\
8 \\
9 \\
10 \\
11 \\
12 \\
13\end{array}$ & $\begin{array}{l}f \\
f \\
\text { f } \\
m \\
m \\
\text { f } \\
m \\
m \\
m \\
\text { f } \\
\text { f } \\
\text { f } \\
\text { f }\end{array}$ & $\begin{array}{l}65 / 67 \\
76 / 79 \\
64 / 66 \\
72 / 74 \\
63 / 65 \\
55 / 69 \\
70 / 72 \\
67 / 68 \\
61 / 67 \\
64 / 65 \\
64 / 65 \\
59 / 64 \\
63 / 65\end{array}$ & $\begin{array}{l}\text { anomia } \\
\text { anomia } \\
\text { anomia/agraphia } \\
\text { anomia } \\
\text { anomia } \\
\text { anomia } \\
\text { anomia } \\
\text { agraphia } \\
\text { dysfluency } \\
\text { dysfluency } \\
\text { dysfluency } \\
\text { anomia } \\
\text { anomia }\end{array}$ & $\begin{array}{l}\text { abn,abn,abn,wnl } \star \star \\
\text { abn,abn,wnl,wnl } \\
\text { abn,abn,abn,wnl } \\
\text { wnl,wnl,wnl,abn } \\
\text { abn,abn,wnl,wnl } \\
\text { abn,abn,wnl,wnl } \\
\text { abn,abn,abn,wnl } \\
\text { abn,abn,wnl,wnl } \\
\text { wnl,abn,wnl,abn } \\
\text { wnl,abn,abn,abn } \\
\text { wnl,abn,abn,abn } \\
\text { abn,abn,abn,wnl } \\
\text { abn,abn,wnl,wnl }\end{array}$ & $\begin{array}{l}\mathbf{N} \\
\mathbf{N} \\
\mathbf{N} \\
\mathbf{A} \\
\mathbf{A} \\
\mathbf{A} \\
\mathbf{A} \\
\mathbf{A} \\
\mathbf{N} \\
\mathbf{N} \\
\mathbf{N} \\
\mathbf{N} \\
\mathbf{N}\end{array}$ & $\begin{array}{l}\text { A } \\
\text { A } \\
\text { A } \\
\text { A } \\
\text { A } \\
\mathbf{N} \\
\mathbf{N} \\
\mathbf{N} \\
\mathbf{A} \\
\mathbf{A} \\
\mathbf{A} \\
\mathbf{A} \\
\mathbf{N}\end{array}$ \\
\hline
\end{tabular}

$\star \mathrm{CAL}=$ calculations; WRT $=$ writing; $\mathrm{REP}=$ repetition; OBA $=$ oral-buccal apraxia ${ }^{\star \star} \mathrm{wnl}=$ within normal limits on presentation; $\mathrm{abn}=$ abnormal on presentation.

neuropsychological testing disclosed multiple cognitive deficits beyond language. A repeat EEG showed occasional epileptiform discharges from the left hemisphere, and she was started on phenytoin. Three years after the onset of aphasia the patient could barely follow simple commands, was very demented, and had extensive myoclonus.

\section{Patient 6}

A 69 year old college professor was reevaluated for a progressive language disorder. Her illness began at the age of 55 when she first noticed difficulty playing Scrabble followed by difficulty finding the right word for the right context. Five years later she also had difficulty with writing and with calculations. She was hypertensive. Neurological examination disclosed a decreased right nasolabial fold, slight right pronator drift, and an equivocal right plantar reflex. She had multiple pauses and a great deal of word-finding difficulty; otherwise, she had long, full, grammatically-correct sentences with some phonemic paraphasias. Confrontational naming was impaired, $17 / 60$ on the Boston Naming Test (BNT), but repetition and comprehension were within normal limits. She wrote in alternating script and print with intermixed capitals, lower case letters, trans- posed letters, and spelling errors. The patient was alert, attentive, oriented, and very aware of her language deficit. Her recent memory was mildly impaired primarily for verbal items. She had impaired praxis involving both upper limbs. Constructions were intact, but she had right-left confusion, finger agnosia, and very abnormal calculations. For example, she could not say how many nickels were in \$1.35, perform any multiplications, or add 14 and 32 .

On the Boston Diagnostic Aphasia Examination, fluency and receptive language skills were intact, but there were word-finding problems even for high frequency words. Neuropsychological tests showed deficits in other areas of cognition consistent with a mild dementia, neurological examination was otherwise normal and a head CT scan showed moderate generalised atrophy only.

\section{Patient 9}

The patient was a 64 year old salesman with a two and a half year history of difficulty in speaking. His only other complaint was a difficulty in writing.

On examination, his speech was stammering and stuttering with very limited verbal output, missed words, and short phrase length. He had a hoarse voice with laboured, poorly articulated, and dysprosodic speech with phonemic substitutions. He could, however, name objects quite quickly and easily and scored within the normal range on the BNT. His repetition was perfect, and his comprehension was preserved from single words to the most complex commands. Major difficulties with writing involved misspellings. On the rest of his mental status examination, memory, calculations, right-left discrimination, and finger agnosia were intact but ideomotor apraxia was present. He had no trouble with a clock drawing and was able to copy a three-dimensional figure without difficulty.

On the Western Aphasia Battery, he had decreased fluency, dysprosody, low-pitch intermittent aphonia, and articulation errors. Oral

Table 2 Characteristics of progressive aphasia in the literature

\begin{tabular}{|c|c|c|c|c|}
\hline Study* & Initial symptom & $\begin{array}{l}\text { L sylvian } \\
\text { atrophy }\end{array}$ & $\begin{array}{l}\text { Clinical } \\
\text { dementia }\end{array}$ & Neuropath findings \\
\hline $\begin{array}{l}\text { Mesulam, } 1982(6) \\
\text { Wechsler, } 1982(1) \\
\text { Heath, 1983(1) } \\
\text { Morris, et al, 1984(10) }\end{array}$ & $\begin{array}{l}\text { anomia (5), PWD (1) } \\
\text { anomia/paraphasia } \\
\text { dysfluency } \\
\text { dysfluency (4), paraphasia (4), } \\
\quad \text { agraphia (1), unkwn (1) }\end{array}$ & $\begin{array}{l}(3) \\
(1) \\
(0) \\
(2 / 2)\end{array}$ & $\begin{array}{l}(5) \\
(1) \\
(0) \\
(8)\end{array}$ & $\begin{array}{l}\text { Non-specific (1) } \\
\text { Pick's } \\
\text { Pick-Alzheimer-Parkinson- } \\
\text { spongioform (4) }\end{array}$ \\
\hline $\begin{array}{l}\text { Gordon and Selnes, } 1984(6) \\
\text { Pogacar and Williams, } 1984(1) \\
\text { Kirshner et al, 1984, } 1987(6)\end{array}$ & $\begin{array}{l}\text { anomia/dysfluency } \\
\text { anomia } \\
\text { anomia (3), abn comprehension } \\
\quad(2) \text {, dysfluency (1) }\end{array}$ & $\begin{array}{l}(2) \\
(1) \\
(2)\end{array}$ & $\begin{array}{l}(4) \\
(1) \\
(6)\end{array}$ & $\begin{array}{l}\text { Alzheimer's } \\
\text { Focal spongioform changes } \\
\text { and mild astrocytosis (2) }\end{array}$ \\
\hline $\begin{array}{l}\text { Shuttleworth et al, } 1985 \text { (1) } \\
\text { Holland } \text { et al, } 1985 \text { (1) } \\
\text { Assal } \text { et al, } 1985(1) \\
\text { Caplan and Richardson, } 1986 \text { (1) } \\
\text { Mehler et al, } 1986 \text { (2) }\end{array}$ & $\begin{array}{l}\text { dysfluency } \\
\text { dysfluency } \\
\text { dysfluency } \\
\text { dysfluency } \\
\text { dysfluency/abn comprehension }\end{array}$ & $\begin{array}{l}\text { (1) } \\
(1) \\
(1) \\
(1) \\
(2)\end{array}$ & $\begin{array}{l}(1) \\
(1) \\
(1) \\
(1) \\
(2)\end{array}$ & $\begin{array}{l}\text { Creutzfeldt-Jakob } \\
\text { Pick's } \\
\text { Pick's } \\
\text { Focal neuronal loss and } \\
\quad \text { gliosis (1) }\end{array}$ \\
\hline $\begin{array}{l}\text { Chawluk et al, } 1986 \text { (2) } \\
\text { Basso et al, } 1988(1) \\
\text { Poeck and Luzzatti, } 1988 \text { (3) } \\
\text { Sapin et al, } 1989(2) \\
\text { Mandell et al, } 1989 \text { (1) } \\
\text { Graff-Radford et al, 1990 (1) } \\
\text { Scheltens et al, 1990 (1) } \\
\text { Green et al, } 1990(8)\end{array}$ & $\begin{array}{l}\text { anomia } \\
\text { anomia } \\
\text { anomia } \\
\text { anomia/dysfluency } \\
\text { abn comprehension } \\
\text { anomia } \\
\text { abn comprehension } \\
\text { anomia (5), dysfluency (2), abn } \\
\text { comprehension (1) }\end{array}$ & $\begin{array}{l}(2) \\
(1) \\
(1) \\
(2) \\
(1) \\
(1) \\
(1)\end{array}$ & $\begin{array}{l}(1) \\
(0) \\
(3) \\
(0) \\
(1) \\
(0) \\
(0)\end{array}$ & $\begin{array}{l}\text { Creutzfeldt-Jakob } \\
\text { Pick's } \\
\text { Pick's } \\
\text { Vascularisation and neuronal } \\
\quad \text { loss (1) }\end{array}$ \\
\hline
\end{tabular}

\# Numbers in brackets indicate number of patients. Number of patients are not specified when items in the table apply to all the patients in the study. 
and verbal agility were poor, and he had a decreased ability to perform skilled movements with his mouth and tongue on command. Neurological examination was otherwise normal. EEG showed mildly dysrhythmic sharp and slow waves from the left hemisphere posteriorly, and CT showed cortical atrophy on the left with moderate ventricular enlargement. By the age of 69 , he was practically mute and compromised in multiple spheres of cognition and in activities of daily living, but could still do calculations briskly and accurately. $\mathrm{He}$ also had oral-buccal dyskinesias not due to medications and a tendency to touch everything with his hands.

\section{Patient 12}

A 64 year old woman complained that for four to five years she could not "get certain words out of my mouth." She also complained of difficulty with calculations.

On examination, the patient had frequent pauses and hesitations during which she frantically searched for synonyms for words that she could not find or remember. She also made frequent paraphasic errors: "kennis" for tennis, "tutbrut" for toothbrush, and "scat cam" for CAT scan. Confrontational naming, repetition, and writing were similarly impaired. The extent of the patient's expressive difficulties were especially striking because she understood quite complicated verbal constructions without difficulty. The patient had normal attention and orientation, excellent recent and remote memory, and well executed constructions. Finger naming and right-left discrimination were normal, but she had decreased praxis in the left hand. Calculations were impaired, and she was unable to indicate how many nickels in $\$ 1.35$ or to perform simple multiplications. Neurological examination was otherwise normal.

EEG showed left temporal slowing. Head CT scan showed atrophy in the left sylvian area corresponding to an area of increased signal on MRI scan. By the age of 64 , mental status and neuropsychological testing documented progression to global aphasia and a dementia with multiple cognitive deficits.

\section{Discussion}

Although aphasia in dementia usually evolves in association with other cognitive deficits, aphasia may herald the onset of a dementing illness. ${ }^{12}$ Our dementia patients presented with an anomic, dysfluent aphasia with phonemic paraphasic errors and relatively preserved comprehension. Some of our patients had prominent acalculia and agraphia early in their course, others had accompanying oral-buccal apraxia and reflex and motor changes, and the majority had focal atrophy of the left sylvian fissure on neuroimaging.

Our patients are similar to those described in the literature as Slowly Progressive Aphasia (see table 2). ${ }^{1-21}$ Both groups have a progressive decline in naming and verbal fluency in the absence of other major cognitive deficits in the initial period. In contrast, our patients may differ from some descriptions of the language characteristics of the dementias. For example, other investigators have described the language decline in Alzheimer's disease as characterised by decreased comprehension, normal repetition, and decreased word-list generation but otherwise preserved fluency. ${ }^{22} 23$

Investigators have debated whether SPA is an early manifestation of dementia or a separate focal language disorder. ${ }^{24}{ }^{25}$ Despite the lack of complete neuropsychological testing and follow up data, $43 / 56(77 \%)$ of patients with SPA reported in the literature developed dementia. Some patients required more than a decade of slow deterioration to show other prominent cognitive impairments. ${ }^{324}$ In addition, our patients indicated that, with early neuropsychological testing or long-term follow up, most patients with a progressive aphasia have dementia with a focal onset in left hemisphere language areas.

The clinical characteristics of our patients indicate a spectrum of disturbances running the length of the left sylvian fissure. Neuroimaging showed atrophy in the left sylvian region, and EEGs frequently demonstrated slowing in the left temporal area. Dysfluency, oral-buccal apraxia, and reflex/motor changes point to more anterior disturbances in the motor areas of the frontal region; whereas, prominent acalculia and early writing problems suggest greater involvement of the inferior parietal region. ${ }^{26-28}$ These characteristics may have clinical significance if they indicate discrete subtypes with greater focal atrophy either in the anterior or posterior end of the sylvian fissure.

Dementia presenting with aphasia and focal left sylvian disease may be due to several dementing illnesses. Of the 18 cases of SPA with some neuropathological evaluation, five had Pick's disease, ${ }^{71} 1520$ two had Alzheimer's disease (AD), ${ }^{10}$ two had Creutzfeldt-Jakob disease, ${ }^{12} 19$ four had familial Pick-AlzheimerParkinson-spongioform changes, ${ }^{8}$ and five others had less specific and non-pathognomonic findings. ${ }^{131116}$ While the high incidence of Creutzfeldt-Jakob disease may be explained on the basis of rapid death and early necropsy, the high incidence of Pick's disease suggests that patients with SPA may be more likely to have this dementia rather than the more common $\mathrm{AD}$. $\mathrm{AD}$, however, is clinically and pathologically variable and occasionally may present with relatively focal cortical deficits. ${ }^{29} 30$ Thus dementia presenting with aphasia is not diagnostic of a specific dementing illness.

In conclusion, several dementias may begin with focal left sylvian disease, a prominent anomic/dysfluent aphasia, and other symptoms attributable to dysfunction in the region of the left sylvian fissure. If neuropsychological tests are done early or patients are followed long enough, dementia is found in most patients with a progressive aphasia. This has prognostic and management implications for patients with this disorder. Future work is needed to evaluate clinicopathological subtypes and whether the patients with a prolonged course of aphasia before dementia have a distinct aetiology for their disorder. 
1 Green J, Morris JC, Sandson J, McKeel DW Jr, Miller JW. Progressive aphasia: A precursor of global dementia?

2 Kirshner HJ, Webb WG, Kelly MP, Wells CE. Language disturbance: an initial symptom of cortical degenerations and dementia. Arch Neurol 1984;41:491-6.

3 Mesulam M-M. Slowly progressive aphasia without generalized dementia. Ann Neurol 1982;11:592-8.

4 Heath PD, Kennedy P, Kapur N. Slowly progressive aphasia without generalized dementia. Ann Neurol 1983; 13:687-8.

5 Chawluk JB, Mesulam M-M, Hurtig H, et al. Slowly progressive aphasia without generalized dementia: studies with positron emission tomography. Ann Neurol 1986; 19:68-74.

6 Poeck K, Luzzatti C. Slowly progressive aphasia in three patients. Brain 1988;111:151-68.

7 Wechsler AF, Verity MA, Rosenscheim S, Fried I, Scheibel AB. Pick's disease: a clinical, computed tomographic and histological study with Golgi impregnation observations. Arch Neurol 1982;39:3287-90.

8 Morris JC, Cole M, Banker BQ, Wright D. Hereditary dysphasic dementia and the Pick-Alzheimer spectrum. Ann Neurol 1984;16:455-66.

9 Gordon G, Selnes O. Progressive aphasia "without dementia": evidence of more widespread involvement. Neurology 1984;34(suppl 1):102.

10 Pogacar S, Williams RS. Alzheimer's disease presenting as slowly progressive aphasia. $R I M e d J 1984 ; 67: 181-5$.

11 Kirshner HS, Tanridag O, Thurman L, Whetsell WO Jr. Progressive aphasia without dementia: two cases with focal spongiform degeneration. Ann Neurol 1987;22: 527-32.

12 Shuttleworth EC, Yates AJ, Paltan-Ortiz JD. CreutzfeldJakob disease presenting as progressive aphasia. J Natl
Med Assoc 1985;77:649-55.

13 Holland AL, McBurney DH, Moossy J, Reinmuth OM. The dissolution of language in Pick's disease with neurofibrillary tangles: a case study. Brain Lang 1985; 24:36-58

14 Assal G, Favre C, Regli F. Aphasie dégénérative. Rev Neurol (Paris) 1985;141:245-7.

15 Caplan LR, Richardson EP Jr. Case Records of the Massachusetts General Hospital (Case 16-1986). N Engl J Med 1986;314:1101-11.

16 Mehler MF, Dickson D, Davies P, Horoupian DS. Primary dysphasic dementia: clinical, pathological and biochemical studies. Ann Neurol 1986;20:126.

17 Basso A, Capitani E, Laiacona M. Progressive language impairment without dementia: a case with isolated category specific semantic defect. J Neurol Neurosurg Psychiatry 1988;51:1201-7.

18 Sapin LR, Anderson FH, Pulaski PD. Progressive aphasia without dementia: further documentation. Ann Neurol 1989;25:411-3.

19 Mandell AM, Alexander MP, Carpenter S. CreutzfeldJakob disease presenting as isolated aphasia. Neurology 1989;39:55-8.

20 Graff-Radford NR, Damasio AR, Hyman BT, et al. Progressive aphasia in a patient with Pick's disease: a neuropsychological, radiologic, and anatomic study. Neurology 1990;40:620-6.

21 Scheltens P, Hazenberg GJ, Lindeboom J, Valk J, Wolters EC. A case of progressive aphasia without dementia: "temporal" Pick's disease? J Neurol Neurosurg Psychiatry "temporal" Pick's

22 Faber-Langendoen K, Morris JC, Knesevich JW, LaBarge E, Berg L. Aphasia in senile dementia of the Alzheimer type. Ann Neurol 1988;23:365-70.

23 Cummings JL, Benson DF, Hill MA, Read S. Aphasia in dementia of the Alzheimer type. Neurology 1985;35: 394-7.

24 Mesulam M-M. Primary progressive aphasia: differentiation from Alzheimer's disease. Ann Neurol 1987;37:1448-53.

25 Foster NL, Chase TN. Diffuse involvement in progressive aphasia. Ann Neurol 1983;13:224-5.

26 Grafman J, Passafiume D, Faglioni P, Boller F. Calculation disturbances in adults with focal hemisphere damage. Cortex 1982;18:37-49.

27 Rosati G, De Bastiani P. Pure agraphia: a discrete form of aphasia. J Neurol Neurosurg Psychiatry 1979;42:266-9.

28 Benson DF, Cummings JL, Tsai SY. Angular gyrus syndrome simulating Alzheimer's disease. Arch Neurol 1982;
dron syn39:616-20

29 Friedland RP, Koss E, Haxby J, et al. Alzheimer's disease: clinical and biological heterogeneity. Ann Int Med 1988; 109:298-311.

30 Celsis P, Agniel A, Puel M, Rascol A, Marec-Vergens J-P. Focal cerebral hypoperfusion and selective cognitive deficit in dementia of the Alzheimer type. $J$ Neurol Neurosurg Psychiatry 1987;50:1602-12. 